\title{
INFLUENCE OF WELDing PARAMETERS ON GEOMETRY AND MICROSTRUCTURE OF LASER-WELDED STEELS WITH INCREASED CARBON CONTENT
}

\author{
Nikola Knezović \& Angela Topić
}
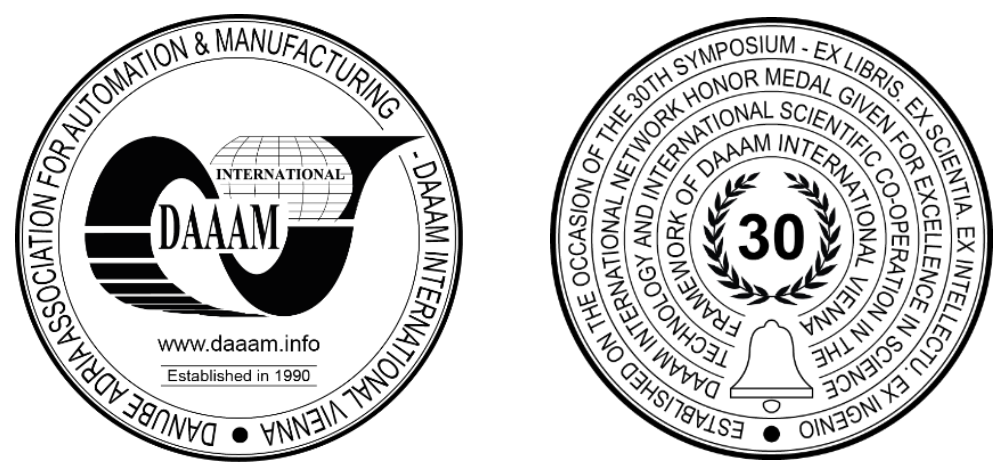

This Publication has to be referred as: Knezović, N[ikola] \& Topić, A[ngela] (2020). Influence of welding parameters on geometry and microstructure of laser-welded steels with increased carbon content, Proceedings of the 31st DAAAM International Symposium, pp.xxxx-Xxxx, B. Katalinic (Ed.), Published by DAAAM International, ISBN 978-3-902734xx-x, ISSN 1726-9679, Vienna, Austria

DOI: $10.2507 / 31$ st.daaam.proceedings.Xxx

\begin{abstract}
Higher strength steels could be used to produce thin sheets since they allow greater load capacity. Laser welding is suitable for welding those thin sheets. Higher power density in laser welding enables welding with a lower specific heat input, but it leads to very high cooling rates, thus increasing the hardness. In this experiment, Nd:YAG laser was used to weld 2 $\mathrm{mm}$ thick heat-treatable steel sheets $25 \mathrm{CrMo} 4$ and $42 \mathrm{CrMo} 4$. These are alloys with higher strength, but also with increased carbon content (and accordingly higher hardness). Carbon is known for its tendency to decrease the weldability of the steel, which is usually a problem in the application of steel grades like these two. Different welding parameters were tested and its influence on geometrical characteristics and microstructure of welded joints is discussed.
\end{abstract}

Keywords: Carbon content; Laser Welding; Microstructure; Higher strength steel; Heat-affected zone

\section{Introduction - problems and current situation}

When it comes to situations when tensile strength and the yield strength of certain structural steel does not satisfy the design requirements, the easiest solution is to choose larger profiles. However, sometimes the limitations of the product do not allow that, since the dimensions and weight of the product should not be increased. The acceptable idea, in that case, is to use higher strength steel. Higher strength is usually obtained with increased carbon content. Their improved strength enables the usage of lighter structures which are in some cases thin sheets [1], [2], [3]. One of the most appropriate welding processes for thin sheets welding is laser welding [4], [5]. The carbon content of about $0.22 \%$ is considered to be an upper margin for good weldability. Steels with higher carbon content are, therefore, more difficult to weld since carbon increases hardness. The hardening should be prevented by using thermal treatment before or after the welding process [6], [7]. Besides that, other problems which occur during the welding of these steels are cracks and weld metal porosity [8]. The application of laser welding in the industry is constantly increasing due to its numerous advantages: great welding speed, negligible deformations of the welded parts and high quality of the welded joint. However, high power density in laser welding enables welding with lower specific heat input compared with conventional welding processes, which leads to a very high cooling rate, which increases hardness even more [9]. 
Due to that, laser welding was not used as much as it could be for high strength steels and that is the reason why there are not so many papers related to this topic. The objective of this research was to determine the influence of the welding parameters and shielding gas (argon and helium) on the geometry and microstructure of the welded joint. If it is possible to find appropriate parameters to produce acceptable geometry (of course, without imperfections or at least with acceptable imperfections) and appropriate microstructure, then there could be a need to further examine mechanical properties to see could this process be used to produce fully functional products made from higher strength steel. Basic limitation of this research was the fact that there were no topic-related papers so the results can not be compared with similar researches. However, the author's approach and idea were to get results that can be used to make some conclusion which will be basis for future researches.

\section{Experimental procedure}

Welding was carried out with laser "ROFIN CW 020" (Nd:YAG type), with the continuous power of $2 \mathrm{~kW}$. The beam was transferred using the optical fibre, with the core diameter of $600 \mu \mathrm{m}$ core diameter was used for the beam transfer. Focusing optics was controlled by the robot "IGM limat RT 280", featuring 6 degrees of movement freedom. The beam diameter in the focus was $0.6 \mathrm{~mm}$.

$2 \mathrm{~mm}$ thick sheets of high strength steels $25 \mathrm{CrMo} 4$ (1.7218) and 42CrMo4 (1.7225) were welded. According to the EN ISO 683-1:2018 standard, their carbon content ranges from 0.22-0.29\% (25CrMo4) and 0.38-0.45\% (42CrMo4). Chemical analysis was done to confirm that, and it showed $0.24 \%$ for $25 \mathrm{CrMo} 4$ and $0.4 \%$ for $42 \mathrm{CrMo} 4$, which is accordant with the standard mentioned. Sheets were cut to dimensions 250x130 mm. The longer sides, that have been welded, were machined and the surfaces were sand-blasted. They were also degreased using $96 \%$ ethanol solution prior to the welding. Other constant parameters were: power $(1800 \mathrm{~W})$, focal length $(120 \mathrm{~mm})$, gas nozzle tip diameter $(5 \mathrm{~mm})$, shielding gas flow (12 1/min for argon and $26 \mathrm{l} / \mathrm{min}$ for helium) and distance of gas nozzle tip from the workpiece (6 mm for argon and $8 \mathrm{~mm}$ for helium). Welding was performed with minimal and maximal power input allowed for certain steel. Heat input is calculated using equation (1):

$$
\mathrm{HI}=60 \mathrm{~W} / \mathrm{v}
$$

where $\mathrm{W}$ is the laser power and $\mathrm{v}$ is welding speed.

Combining shielding gases and welding speeds, a total of eight states of the experiment was obtained, which is given in Table 1 .

\begin{tabular}{|c|c|c|c|c|}
\hline Specimen & Material & Shielding gas & Shielding gas flow & Welding speed \\
\hline 1 & $25 \mathrm{CrMo} 4$ & Argon & $121 / \mathrm{min}$ & $110 \mathrm{~cm} / \mathrm{min}$ \\
\hline 2 & $25 \mathrm{CrMo} 4$ & Argon & $121 / \mathrm{min}$ & $150 \mathrm{~cm} / \mathrm{min}$ \\
\hline 3 & $25 \mathrm{CrMo} 4$ & Helium & $261 / \mathrm{min}$ & $110 \mathrm{~cm} / \mathrm{min}$ \\
\hline 4 & $25 \mathrm{CrMo} 4$ & Helium & $261 / \mathrm{min}$ & $150 \mathrm{~cm} / \mathrm{min}$ \\
\hline 5 & $42 \mathrm{CrMo} 4$ & Argon & $121 / \mathrm{min}$ & $90 \mathrm{~cm} / \mathrm{min}$ \\
\hline 6 & $42 \mathrm{CrMo} 4$ & Argon & $121 / \mathrm{min}$ & $130 \mathrm{~cm} / \mathrm{min}$ \\
\hline 7 & $42 \mathrm{CrMo} 4$ & Helium & $261 / \mathrm{min}$ & $90 \mathrm{~cm} / \mathrm{min}$ \\
\hline 8 & $42 \mathrm{CrMo} 4$ & Helium & $261 / \mathrm{min}$ & $130 \mathrm{~cm} / \mathrm{min}$ \\
\hline
\end{tabular}

Table 1. States of the experiment

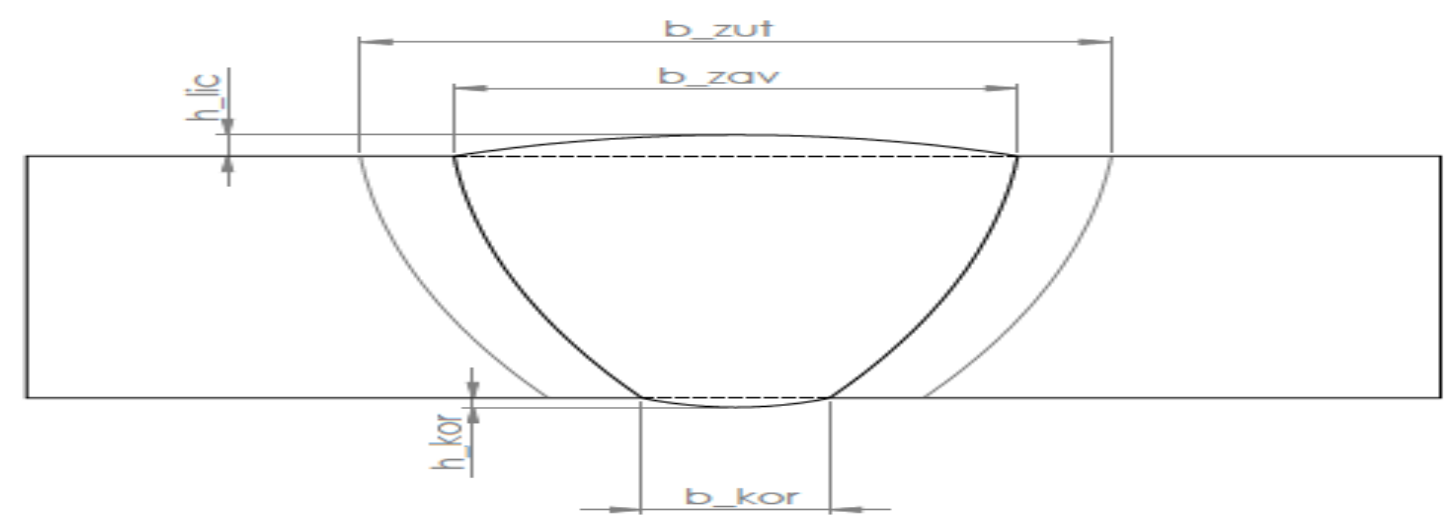

Fig. 1. Measured geometry characteristics 
The welded samples have been visually inspected for possible surface imperfections and then were subjected to metallographic analysis to reveal joint geometry and microstructure of weldment. Samples for analysis were macrosections, prepared by grinding and polishing prior to the etching in the 5\% solution of nitric acid $\left(\mathrm{HNO}_{3}\right)$ in ethanol. Geometry measuring was done using LECO Image Analyzer and microstructure characterisation was done using a light microscope (magnification 500x). Measured geometry characteristics are shown in Figure 1. b_zav is weld width, b_zut is heat affected zone width, b_kor is root width, h_lic is weld face height and h_kor is weld root height

\section{Results and discussion}

Values of geometrical characteristics are shown in Table 2 (in millimetres).

\begin{tabular}{|c|c|c|c|c|c|}
\hline Specimen & b_zav & b_kor & b_zut & h_lic** & h_kor \\
\hline $\mathbf{1}$ & 1.94 & 0.92 & 2.74 & 0.11 & 0.07 \\
\hline $\mathbf{2}$ & 1.42 & 0.61 & 2.10 & -0.05 & 0.11 \\
\hline $\mathbf{3}$ & 1.86 & 0.82 & 2.80 & 0 & 0.10 \\
\hline $\mathbf{4}$ & 1.33 & 0.47 & 2.09 & 0.11 & 0.13 \\
\hline $\mathbf{5}$ & 2.22 & 0.99 & 3.27 & 0.10 & 0.17 \\
\hline $\mathbf{6}$ & 1.72 & 0.71 & 2.39 & 0 & 0.19 \\
\hline $\mathbf{7}$ & 2.08 & 0.80 & 3.21 & 0.08 & 0.11 \\
\hline $\mathbf{8}$ & 1.75 & 0.46 & 2.34 & -0.08 & 0.16 \\
\hline
\end{tabular}

Table 2. Values of measured geometrical characteristics (* “_" means there is a sag on weld face).

All values marked with "b" are widths, which means they can not be zero, but it is preferable them to be lower (if the width of weld or root or heat affected zone is lower, it means base material is less affected with the welding process). Considering that, it can be concluded that specimens 5 and 7 are the worst ones since they have the largest b_zav and b_zut. Also, specimen 5 has the largest b_kor. Both of these specimens were welded with lower welding speed. Specimens 1 and 3 have larger widths than specimens 2 and 4, and they were also welded with lower speed.

All values marked with " $\mathrm{h}$ " are heights and they are preferable to be zero. If face height is higher, there are cambers on the weld and if it is lower, there are sags. If root height is higher, there is excessive penetration and if it is lower, there is not enough penetration. Considering that, only specimen 3 is acceptable. Specimen 6 does not have any camber or sag on the face, but it has the worst root (excessive penetration). Also, it is extremely important to emphasize that some surface porosity was observed with visual testing (even only with the naked eye). All the specimens welded with argon as shielding gas have shown porosity and none of the specimens welded with helium used has shown the same.

However, all these values are not so excessive, which means these parameters could be used to produce welds on higher strength steels like these. Figure 2 shows specimens without camber or sag (3), the specimen with camber (4) and the specimen with sag (8).

3

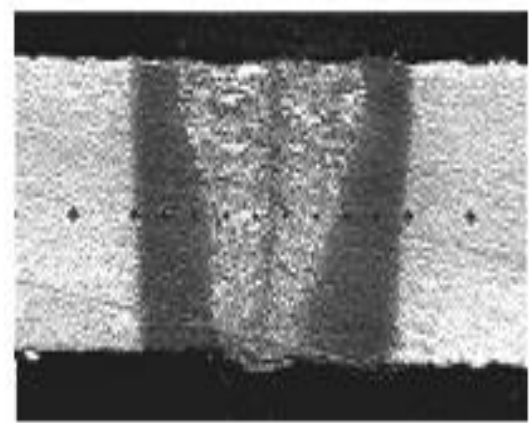

4

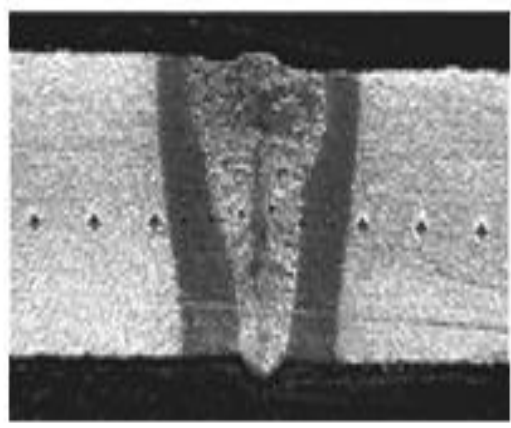

8

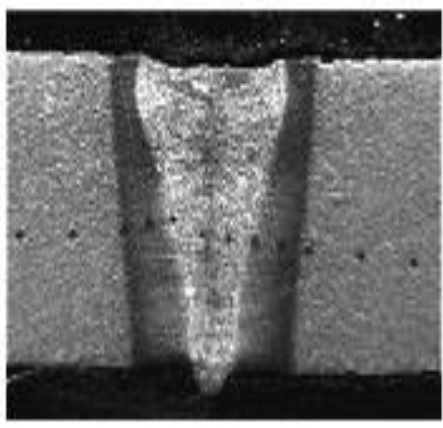

Fig. 2. Specimens with different geometrical characteristics

The microstructure of the base material was mostly ferrite, with some martensite. During the welding, carbon content tends to increase which means there should be more martensite, thus increasing hardness. The goal of the microstructure characterisation was to examine is that true. Figure 3 shows microstructures of some specimens. There was no need to show all specimens since they are all almost the same - they are all made of mostly martensitic phase. Considering mechanical properties, this is the indicator of bad news - probably the hardness increased too much (martensite is the hardest phase in steel). However, this should be confirmed by testing hardness, tensile strength or impact toughness. 


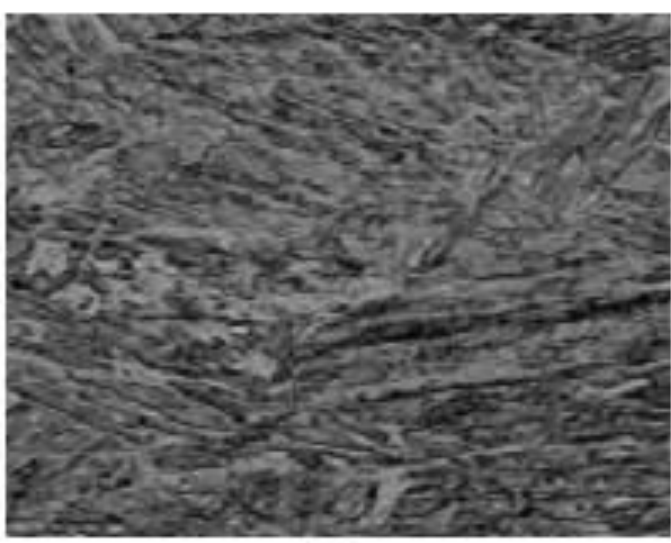

1

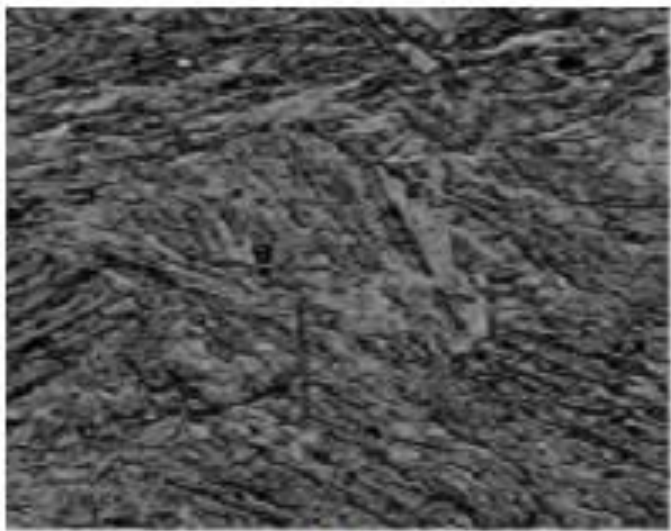

2

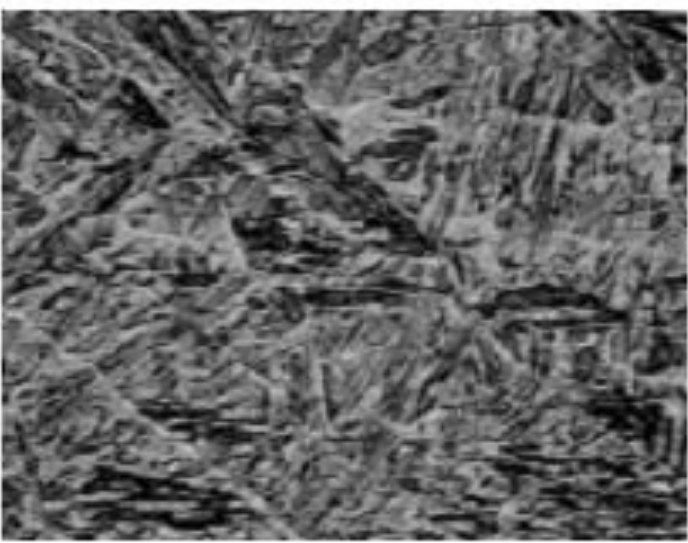

5

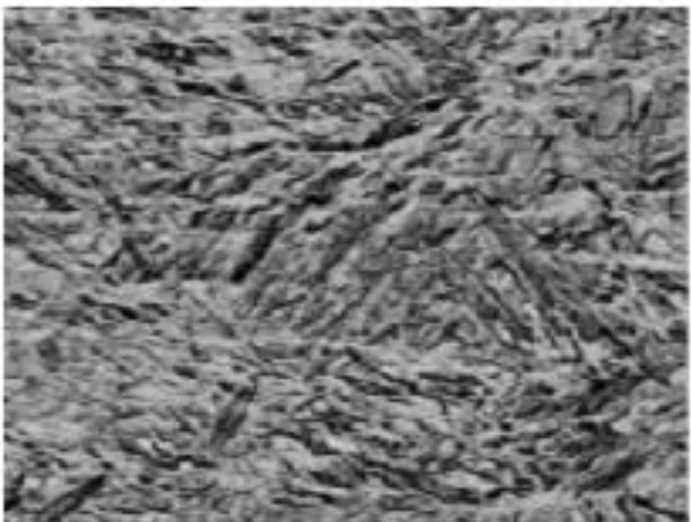

6

Fig. 3. The microstructure of some specimens

The main problem for this paper, as it is already said in Introduction, is the fact that there were no enough findings from other papers, so these results could not be compared with some similar researches. However, the main goal of the paper was accomplished - it is possible to obtain appropriate parameters to produce welded joint with acceptable geometry (without imperfections, or at least with acceptable imperfections). Microstructure still needs to be improved, since the martensitic structure obtained with these parameters could deteriorate mechanical properties (impact toughness). This research proved there is a need to further examine mechanical properties. If some of them are found to be acceptable, then this process could be used to produce fully functional products made from higher strength steel.

\section{Conclusions and suggestions}

After studying and discussing the results, there are few conclusion to make and some suggestions to offer guidelines for further researches:

- all specimens welded with lower welding speed have shown greater widths (weld, root and heat affected zone). In the future, higher welding speed should be favourable;

- all specimens welded using argon as shielding gas have some porosity. Pores are not large (the largest one is $0.4 \mathrm{~mm}$ in diameter), but this could mean that helium is a better choice for shielding gas;

- the microstructure of all specimens is almost the same - they all have mostly martensite. It is no problem by itself, but it could mean that hardness is higher than expected, which could lead to a poor impact toughness.

Generally, the conclusion is that higher welding speed is suggested with helium as shielding gas. Since the microstructure is almost the same, it is obvious that these factors do not affect it.

Further researches should include:

- hardness testing;

- tensile strength testing;

- impact toughness testing;

- developing of a mathematical model to describe the relationship between welding parameters and results obtained. 


\section{Literature}

[1] Baluch, N., Udin, Z.M. \& Abdullah, C.S. (2014) Advanced high strength steel in auto industry: an overview. Engineering, Technology \& Applied Science Research. Vol. 4, No. 4, 2014, pp. 686-689, 1792-8036

[2] Chiew, S.P., Zhao, M.S. \& Lee, C.K. (2014) Mechanical properties of heat-treated high strength steel under fire/postfire conditions. Journal of Constructional Steel Research. Vol. 98, 2014, pp. 12-19, 0143-974X

[3] Janda, T., Jirkova, H. \& Jenicek, S. (2018). Comparing Properties of the 42SiCr Steel After Conventional Heat Treatment and QP Processing, Proceedings of the 29th International DAAAM Symposium "Intelligent Manufacturing \& Automation", Zadar, ISSN: 1726-9679, ISBN: 978- 3-902734-20-4, B. Katalinic (Ed.), pp.11641167, Published by DAAAM International, Vienna, 10.2507/29th.daaam.proceedings. 167

[4] Bakir, N., Pavlov, V., Zavjalov, S., Volvenko, S., Gumenyuk, A., \& Rethmeier M. (2018) Novel metrology to determine the critical strain conditions required for solidification cracking during laser welding of thin sheets. Journal of Physics Conference Series. Vol. 1109, 2018, 1742-6596

[5] Casalino G. \& Mortello, M. (2016). A FEM model to study the fiber laser welding of Ti6Al4V thin sheets. The International Journal of Advanced Manufacturing Technology. Vol. 86, 2016, pp. 1339-1346, 1433-3015

[6] Divinski, S.V., Reglitz, G., Golovin, I.S., Peterlechner, M., Lapovok, R., Estrin, Y. et al. (2015) Effect of heat treatment on diffusion, internal friction, microstructure and mechanical properties of ultra-fine-grained nickel severely deformed by equal-channel angular pressing. Acta Materialia. Vol. 82, 2015, pp. 11-21, 1359-6454

[7] Topić, A., Bauer, B., Kožuh, Z., \& Knezović, N. (2016). Gas composition influence on the microstructure and geometry of laser-welded joints in duplex stainless steel, Proceedings of 27th International DAAAM Symposium "Intelligent Manufacturing \& Automation", Mostar, ISSN: 1726-9679, ISBN: 978-3-902734-08-2, Katalinic, B. (Ed.), pp. 734-742., DAAAM International, Vienna, 10.2507/27th.daaam.proceedings.106

[8] Wang, X.N., Chen, X.M., Sun, Q., Di, H.S., Sun, L.N. (2017) Formation mechanism of $\delta$-ferrite and metallurgy reaction in molten pool during press-hardened steel laser welding. Materials Letters. 2017, Vol. 206, pp. 143-145, 0167-577X

[9] Markashova, L., Berdnikova, O., Bernatskyi, A., Iurzhenko, M. \& Sydorets V. (2017) Physical and mechanical properties of high-strength steel joints produced by laser welding. Proceedings of 2017 IEEE International Young Scientists Forum on Applied Physics and Engineering (YSF), Lviv. ISBN: 978-1-538629-94-9, pp. 88-91. IEEE, 10.1109/YSF.2017.8126596 